\title{
Geographic difference in safety and efficacy of systemic chemotherapy for advanced gastric or gastroesophageal carcinoma: a meta-analysis and meta-regression
}

\author{
Chiun Hsu $\cdot$ Ying-Chun Shen $\cdot$ Chia-Chi Cheng $\cdot$ \\ Ann-Lii Cheng $\cdot$ Fu-Chang Hu $\cdot$ Kun-Huei Yeh
}

Received: 8 March 2011/ Accepted: 23 September 2011/Published online: 8 February 2012

(c) The International Gastric Cancer Association and The Japanese Gastric Cancer Association 2012

\begin{abstract}
Background The standard of chemotherapy regimens for advanced or metastatic gastric cancer and the clinical outcome were heterogeneous in Asian versus non-Asian countries. This study aimed to explore predictors of safety and efficacy of chemotherapy for patients with advanced or metastatic gastric cancer.

Methods Treatment group-based meta-analysis and metaregression were performed to analyze results of randomized trials published since 2005 for advanced or metastatic gastric cancer patients who received systemic chemotherapy as first-line treatment. Data were extracted and synthesized according to the Cochrane guidelines.

Results Twenty-five trials (8 Asian, 17 Western or international) with 56 treatment groups were analyzed.
\end{abstract}

C. Hsu and Y.-C. Shen contributed equally to this work.

Electronic supplementary material The online version of this article (doi:10.1007/s10120-011-0106-5) contains supplementary material, which is available to authorized users.

C. Hsu · A.-L. Cheng · K.-H. Yeh (ه)

Department of Oncology, National Taiwan University Hospital,

7 Chung-Shan South Road, Zhongzheng District,

Taipei 100, Taiwan

e-mail: khyeh@ntu.edu.tw

C. Hsu $\cdot$ A.-L. Cheng

Department of Internal Medicine, National Taiwan University

Hospital, Taipei, Taiwan

\section{Y.-C. Shen}

Graduate Institute of Toxicology, College of Medicine,

National Taiwan University, Taipei, Taiwan

Y.-C. Shen · C.-C. Cheng · A.-L. Cheng

Department of Medical Research, National Taiwan University

Hospital, Taipei, Taiwan
Asian trials reported a lower percentage of gastroesophageal junctional carcinoma, higher percentage of diffusetype histology, and more frequent use of second-line chemotherapy. Meta-analysis revealed significant heterogeneity both in treatment safety (grade 3-4 neutropenia and diarrhea) and efficacy [6-month progression-free survival (PFS) and 1-year overall survival (OS)]. Meta-regression analyses indicate that Asian trials are associated with an 8.2\% lower incidence of grade 3-4 neutropenia and 2.1\% lower incidence of grade 3-4 diarrhea. A lower percentage of patients with gastroesophageal junction carcinoma and the use of combination regimens predicted better PFS. The use of second-line chemotherapy predicts better 1-year OS, which will increase by $10 \%$ for every $10 \%$ increase in patients who received second-line chemotherapy.

Conclusion Geographic region (Asian vs. non-Asian) is an independent predictor of safety in systemic therapy for gastric cancer.

\author{
A.-L. Cheng · K.-H. Yeh \\ Graduate Institute of Oncology, College of Medicine, \\ National Taiwan University, Taipei, Taiwan \\ F.-C. Hu ( $\square)$ \\ International Harvard Statistical Consulting Company, 57 \\ Chongqing South Road, Section 1, 7F-11, \\ Zhongzheng District, Taipei 100, Taiwan \\ e-mail: fuchang.hu@gmail.com \\ F.-C. $\mathrm{Hu}$ \\ Graduate Institute of Clinical Medicine, \\ College of Medicine, National Taiwan University, \\ Taipei, Taiwan
}


Keywords Gastric carcinoma - Gastroesophageal carcinoma $\cdot$ Chemotherapy $\cdot$ Meta-analysis $\cdot$ Metaregression

\section{Introduction}

Combination chemotherapy is the treatment of choice for patients with advanced or metastatic gastric or gastroesophageal carcinoma because of the survival benefit demonstrated by previous clinical trials and meta-analyses $[1,2]$. The availability of multiple active drugs, including fluoropyrimidines, platinum, anthracyclines, taxanes, and irinotecan, encourages clinical trials of combination chemotherapy for both advanced diseases and for adjuvant/ neoadjuvant therapy [3]. However, heterogeneity issues in clinical trial design and patient population, which are important confounding factors of gastric cancer trials, are not adequately addressed in previous analyses [4].

The first source of heterogeneity is a lack of international consensus on the optimal chemotherapeutic regimens. Cisplatin-fluoropyrimidine combinations are used in many international clinical trials as the control arm treatment, but the types (parenteral or oral) and dosage of fluoropyrimidines vary widely. Many studies were done to compare the efficacy, safety, and pharmacological characteristics of different fluoropyrimidine regimens, but the optimal regimen remains undetermined [5-8]. Addition of epirubicin or docetaxel to the platinum-fluoropyrimidine combination is common in Europe and the USA because of the survival benefit demonstrated by randomized clinical trials [9-11], but it is still under debate whether the survival benefit justifies the additional toxicity of these threedrug combinations.

A second source of heterogeneity is the regional and ethnic difference in the clinical outcome and treatment strategies $[12,13]$. The incidences of different subtypes of gastric cancers (intestinal type vs. diffuse type, non-cardiac location vs. cardiac/gastroesophageal junctional location) differ between Asian and non-Asian populations. These different subtypes of gastric cancers are associated with different risk factors, clinical presentation, and treatment outcomes [14-17]. Therefore, clinical trials conducted in different regions of the world may enroll patients with heterogeneous biological backgrounds that make the trial results not comparable. In addition, the incidences of genetic polymorphisms of genes involved in drug metabolism, including those for fluoropyrimidines, taxanes, and platinums, also differ between Asian and non-Asian populations [18-20]. These differences may result in different drug disposition, tolerance to the same chemotherapeutic agents, and preference of Asian and non-Asian investigators in choosing the optimal combinations.
Meta-analysis, which combines results from multiple studies to estimate the treatment outcome, is usually used to explore the heterogeneity issue. Ideally such exploration should be based on individual patient data obtained from the original clinical trials, but collection of individual patient data is time-consuming, and pertinent patient data may not be recorded in a standardized way and are usually not available from all relevant trials [21-24]. Meta-analysis based on aggregated patient data, on the other hand, is more feasible to perform, and the heterogeneity issue is analyzed by sub-group analysis. The major drawback of this approach includes loss of statistical power due to decreased sample size in each subgroup and inability to measure the potential interactions between different patient and treatment variables.

A third approach is to perform meta-regression based on aggregated patient data. Meta-regression combines the meta-analytic and linear regression methods to detect the existence and direction of the association between patient and treatment variables and treatment outcome. It can analyze simultaneously the effects of multiple pertinent variables on the outcome as well as the potential interaction among these variables using all the available observations together. Therefore, meta-regression is more efficient statistically than conventional sub-group analysis.

To address these heterogeneity issues in gastric cancer trials, we performed a systematic review on recently published randomized trials of systemic chemotherapy as firstline therapy for gastric or gastroesophageal carcinoma. The purpose of this study is to identify pertinent factors that can help predict safety and efficacy of combination chemotherapy by using meta-analysis and meta-regression, which were done according to the Cochrane guidelines [25]. The potential confounding effects of chemotherapeutic regimens and regional/ethnic difference in treatment strategies were explored.

\section{Methods}

Databases and searches

The electronic databases searched included MEDLINE and PubMed. The search strategy was a combination of the MESH terms 'stomach neoplasms' and 'randomized controlled trial.' Manual search was done in the reference lists of all identified papers (research articles and review papers) as well as the abstracts presented in the annual meetings and gastrointestinal cancer symposiums of the American Society of Clinical Oncology from 2005 to 2009. 
Study selection

The studies were selected for review if they fulfilled the following inclusion criteria: (1) randomized controlled trials published since 2005 that enrolled patients with advanced or metastatic gastric or gastroesophageal carcinoma, and (2) trials testing the safety and efficacy of systemic chemotherapy as the first-line treatment. Trials published before 2005 have been summarized in previous meta-analyses [1, 10]. In addition, the standard of supportive care may change over the years, and this change may confound the interpretation of the meta-analysis results.

\section{Data extraction and synthesis}

Two authors (C.H. and Y.C.S.) did the literature search, data extraction, evaluation, and summary independently. Any disagreement between them was resolved through discussion. The data of the following patient and treatment variables, if available, were extracted from the published reports: patient age, male percentage, geographic regions (Asian vs. non-Asian trials), performance status, tumor stage at enrollment (unresectable vs. recurrent disease after surgery, locally advanced vs. metastatic disease), percentage of diffuse-type histology, percentage of gastroesophageal junctional location, percentage of patients with two or more organs involved, prior treatment before enrollment, types of chemotherapeutic agents studied, and percentage of patients who received second-line chemotherapy. A quality score was generated for each study based on the Cochrane guidelines (Online Resource Supplementary Table 1), with higher quality scores indicating poorer study quality.

Patients who received fluoropyrimidines or platinums were further categorized to explore the potential difference between different dosing regimens of the same type of chemotherapeutic agents. Fluoropyrimidine regimens were categorized as conventional 5-fluorouracil (5FU) regimens (e.g., $5 \mathrm{FU} 800-1,000 \mathrm{mg} / \mathrm{m}^{2} /$ day continuous infusion for 5 days, every 4 weeks or $200 \mathrm{mg} / \mathrm{m}^{2} /$ day continuous infusion), weekly or biweekly infusional high-dose 5FU (e.g., $5 \mathrm{FU} 2,600 \mathrm{mg} / \mathrm{m}^{2}$, 24-h continuous infusion, every 1-2 weeks), and oral fluoropyrimidines (capecitabine or S-1). Platinum regimens were categorized as cisplatin and oxaliplatin.

Each treatment arm in a trial was considered an individual treatment group to compare with one another. The safety endpoints analyzed included the percentage of grade 3-4 neutropenia, febrile neutropenia, diarrhea, nausea/ vomiting, and mucositis because they were reported in most of the clinical trials. The efficacy endpoints analyzed include 6-month progression-free survival (PFS) rate and 1-year overall survival (OS) rate.
Statistical analysis

Statistical analysis proceeded in two steps [26]. First, metaanalysis was conducted with the consideration of both fixed and random effects models, respectively. Then, metaregression was performed to identify the most pertinent variables that predicted safety and efficacy. Variables incorporated in the meta-regression analysis included the following: patient age, male percentage, geographic regions, trial quality score, performance status, tumor stage at enrollment, percentage of diffuse-type histology, percentage of gastroesophageal junctional location, percentage of patients with two or more organs involved, prior treatment before enrollment, types of regimens (single-agent vs. 2-drug combination vs. 3-drug combination), types of chemotherapeutic agents, and percentage of patients who received second-line chemotherapy.

In the meta-regression models, the parameter estimates of each factor indicate the influence (the effect size) of each factor on the outcome. For categorical variables (such as the geographic regions), the parameter estimates indicate the effect size with the presence of individual variables. For continuous variables (such as the percentage of patients who received second-line chemotherapy), the parameter estimates indicate the effect size with each incremental unit (e.g., percentage) of the particular variables. The generalized additive models were used to detect the potential non-linear effects of continuous variables if necessary [27].

Basic model-fitting techniques for variable selection, assessment of goodness-of-fit, and regression diagnostics were used to assure the quality of analysis results, as described before [28, 29]. The meta-analysis and metaregression were done using the Cochrane Review Manager (RevMan) software, version 4.2 (Oxford, UK), the SAS statistical software (version 9.1.3, SAS Institute Inc., Cary, $\mathrm{NC}$, USA), and the R statistical software version 2.6.1 (The R Project for Statistical Computing, http://www.r-project. org/). Two-sided $P$ value $\leq 0.05$ was considered statistically significant.

\section{Results}

Characteristics of studies included in meta-analysis

The data extraction process and the selection of studies were shown in Fig. 1. Twenty-five trials, enrolling 6,792 patients in total, were eligible for meta-analysis [30-53] (Table 1, Online Resource Supplementary Table 2). Eight trials were performed in Asian countries and 13 in Europe or in the USA. Four trials were performed in both Asian and non-Asian population. The percentage of Asian 


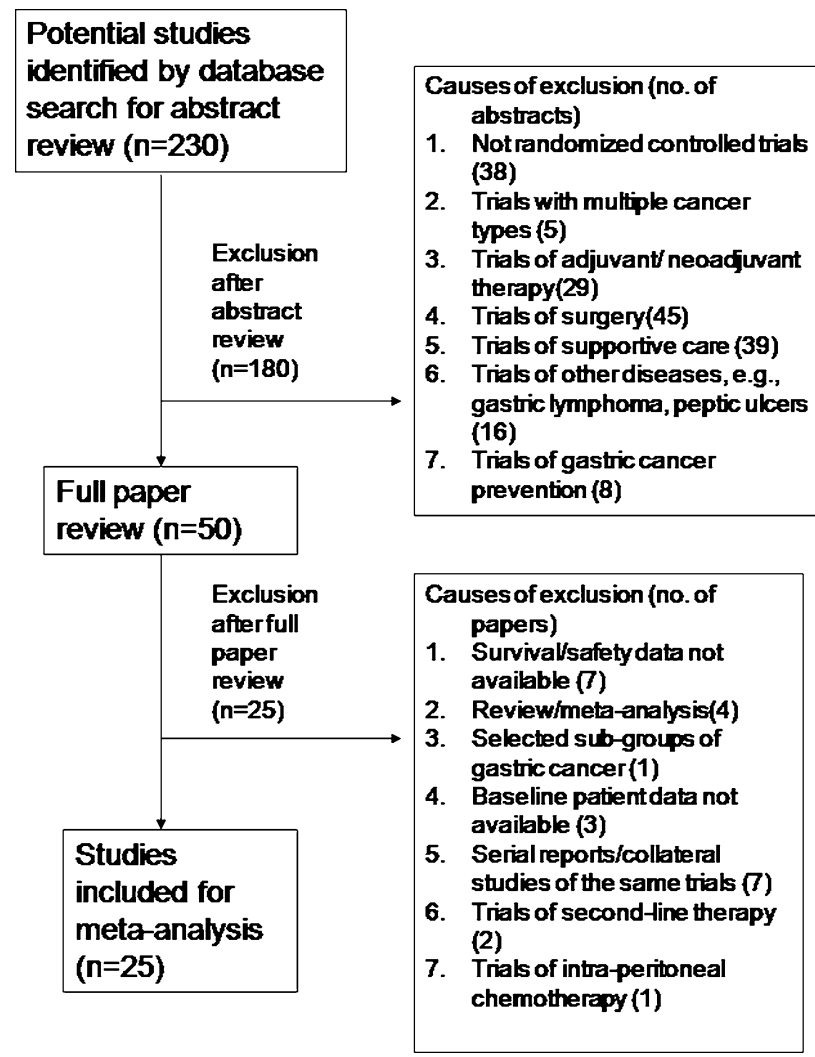

Fig. 1 Study flow chart of the data extraction process and selection of studies for meta-analysis

patients enrolled was reported in three trials (54\% [30], $0.8 \%$ [31], and 66\% [35], respectively).

There were no significant differences between the Asian and non-Asian trials in terms of patient age, male percentage, performance status, tumor stage at enrollment (unresectable vs. recurrent disease after surgery, locally advanced vs. metastatic disease), percentage of organs involved, and treatment before enrollment. Asian trials generally do not enroll patients with gastroesophageal junctional carcinoma, while non-Asian trials enrolled a mean of $18.8 \%$ patients with gastroesophageal junctional carcinoma. In trials that reported the percentage of patients with Lauren's diffuse-type histology (15 trials) and the use of second-line chemotherapy (11 trials), Asian trials reported significantly higher percentage of diffuse-type histology (mean 57.3 vs. $22.0 \%, P<0.001$ ) and more common use of second-line chemotherapy (mean 72.1 vs. $33.9 \%, P=0.001)$ than non-Asian trials.

The 25 trials analyzed consisted of 56 treatment groups. The ToGA trial aimed to evaluate the efficacy of adding trastuzumab to chemotherapy in human epidermal growth factor receptor 2 (HER2)-positive advanced gastric or gastroesophageal junction cancer [30]. Only the patients in the control group, who received chemotherapy alone, were included in this meta-analysis. The choice of regimens differs significantly between Asian and non-Asian trials (see Online Resource Supplementary Table 3). Asian trials used single-agent therapy more frequently, while a threedrug combination was tested in only one treatment group. For the individual chemotherapeutic agents, Asian trials did not incorporate anthracycline as first-line therapy and used platinum less frequently than non-Asian trials.

Safety

Asian trials reported lower incidences of grade 3-4 neutropenia $(19.3 \pm 15.8$ vs. $35.5 \pm 25.5 \%, P<0.0001$ by two-sample test weighted by the patient number in each treatment group), febrile neutropenia $(6.7 \pm 7.1$ vs. $11.2 \pm 9.7 \%, \quad P=0.049), \quad$ diarrhea $(7.4 \pm 6.5 \quad$ vs. $8.3 \pm 6.6 \%, P=0.042)$, and nausea/vomiting $(6.7 \pm 7.1$ vs. $11.2 \pm 9.7 \%, P<0.0001)$. The forest plots of metaanalysis on grade 3-4 neutropenia and diarrhea are shown in Fig. 2. The meta-regression models indicate that geographic region (Asian vs. non-Asian trials) is an independent predictor of neutropenia, febrile neutropenia, and diarrhea (Table 2, Online Resource Supplementary Table 4). After controlling other patient or treatment factors, Asian trials are associated with $8.2 \%$ lower incidence of grade 3-4 neutropenia $(P<0.0001), 2.1 \%$ lower incidence of grade $3-4$ diarrhea $(P<0.0001)$, and $2.2 \%$ lower incidence of febrile neutropenia $(P=0.03)$. The difference in the incidence of nausea/vomiting results mainly from the different chemotherapeutic agents used (Supplementary Table 4).

The use of a three-drug combination, compared with a single-agent or two-drug combination, increased the incidence of grade 3-4 neutropenia by $14.8 \%$. Chemotherapeutic agents that independently increase the risk of grade 3-4 neutropenia include cisplatin, irinotecan, and taxanes. A notable exception is the use of weekly or biweekly highdose infusional 5FU, which is associated with a $12.3 \%$ lower incidence of grade 3-4 neutropenia, compared with other fluoropyrimidine regimens. Irinotecan independently increases the risk of grade 3-4 diarrhea by $16.4 \%$, compared with regimens not using irinotecan. Effects of other agents on the incidence of diarrhea, while statistically significant, are relatively small.

\section{Treatment efficacy}

The reported 1-year OS rates are significantly higher in Asian than non-Asian trials $(45.0 \pm 10.3$ vs. $35.5 \pm 10.6 \%$, $P<0.0001$ by two-sample $t$ test weighted by the patient number in each treatment group). By contrast, the 6-month PFS rates are significantly lower in Asian than non-Asian trials $(35.7 \pm 11.8$ vs. $41.0 \pm 7.3 \%, P=0.004)$. The forest plots of meta-analysis on 1-year OS and 6-month 


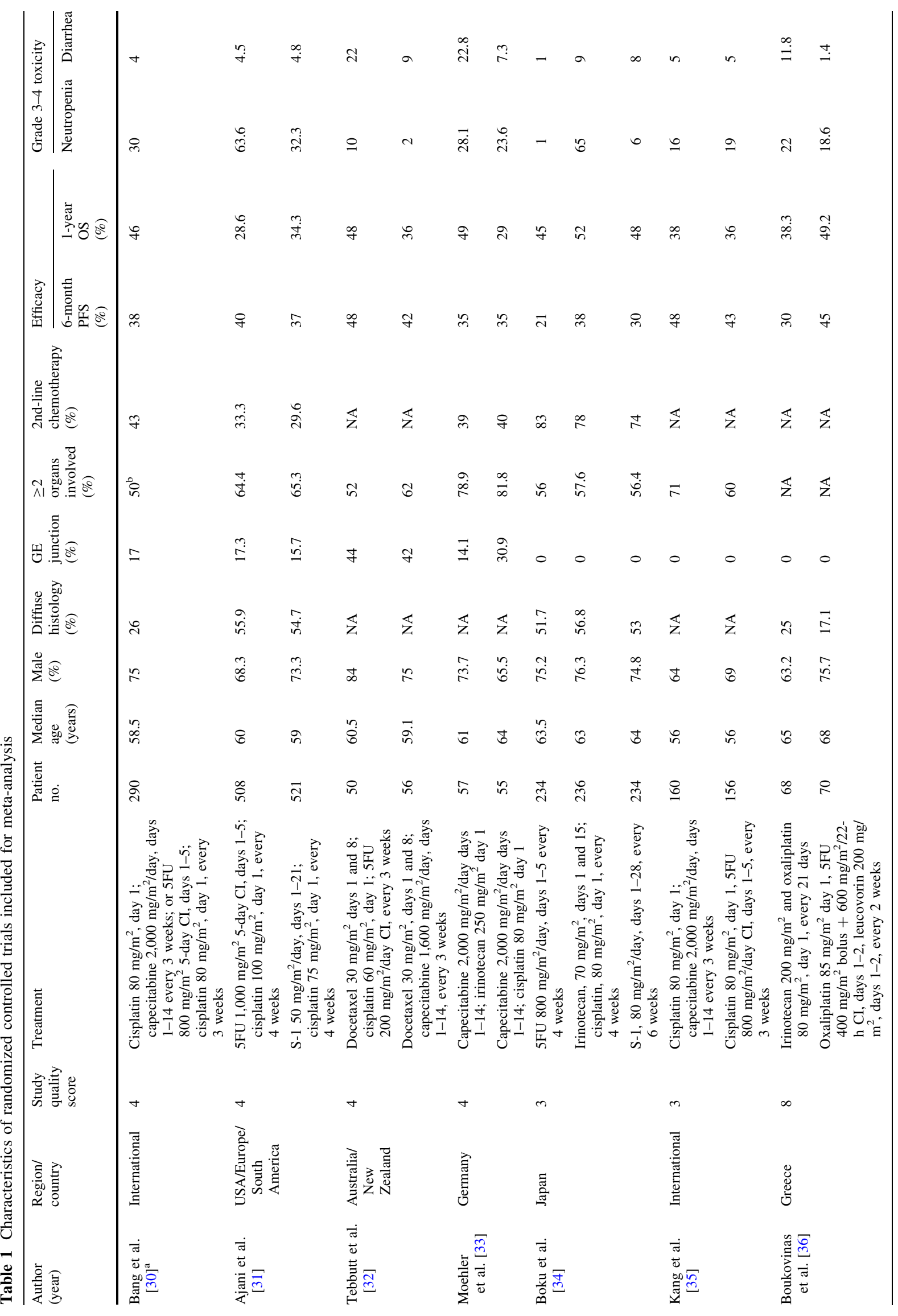




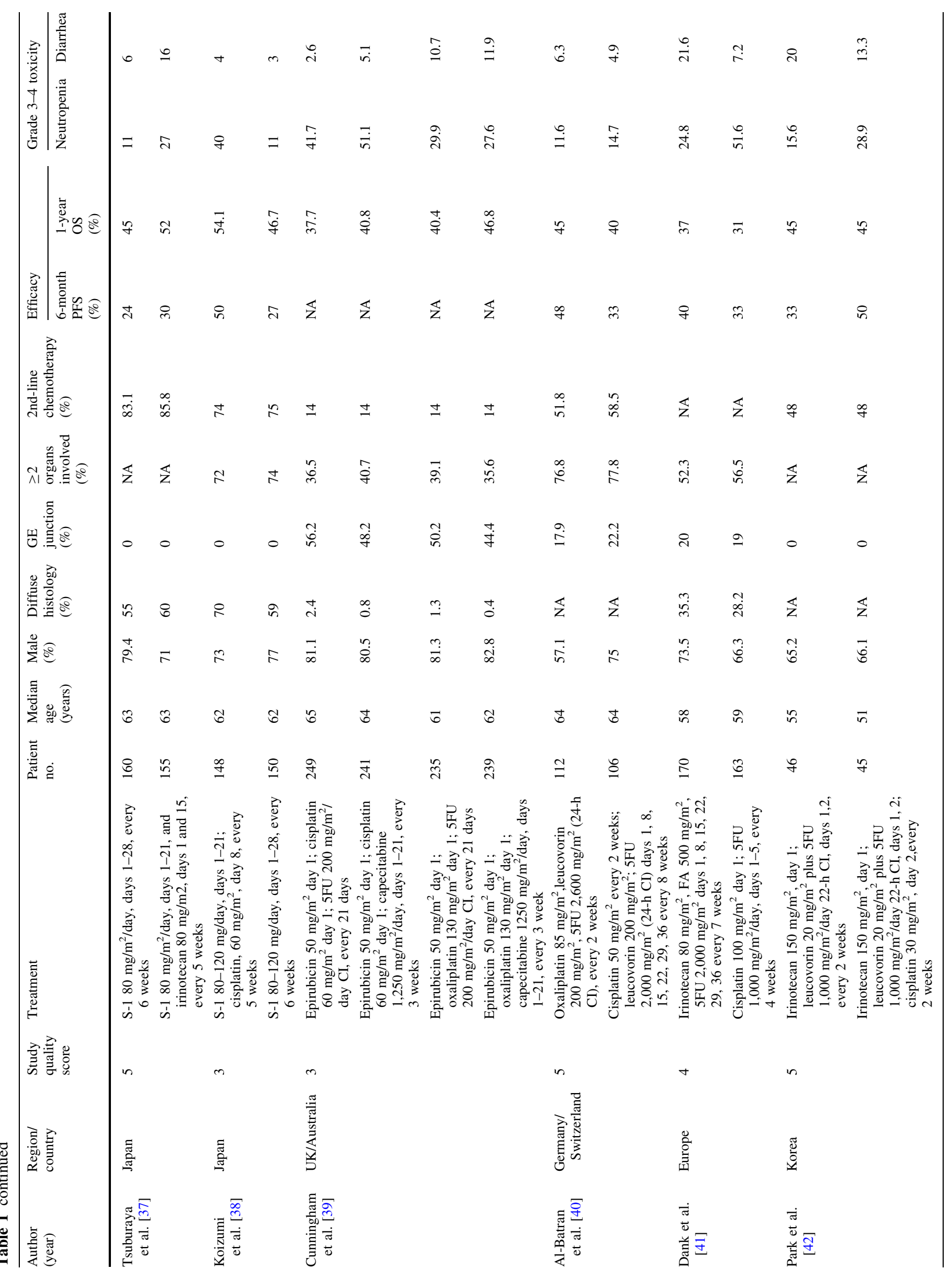




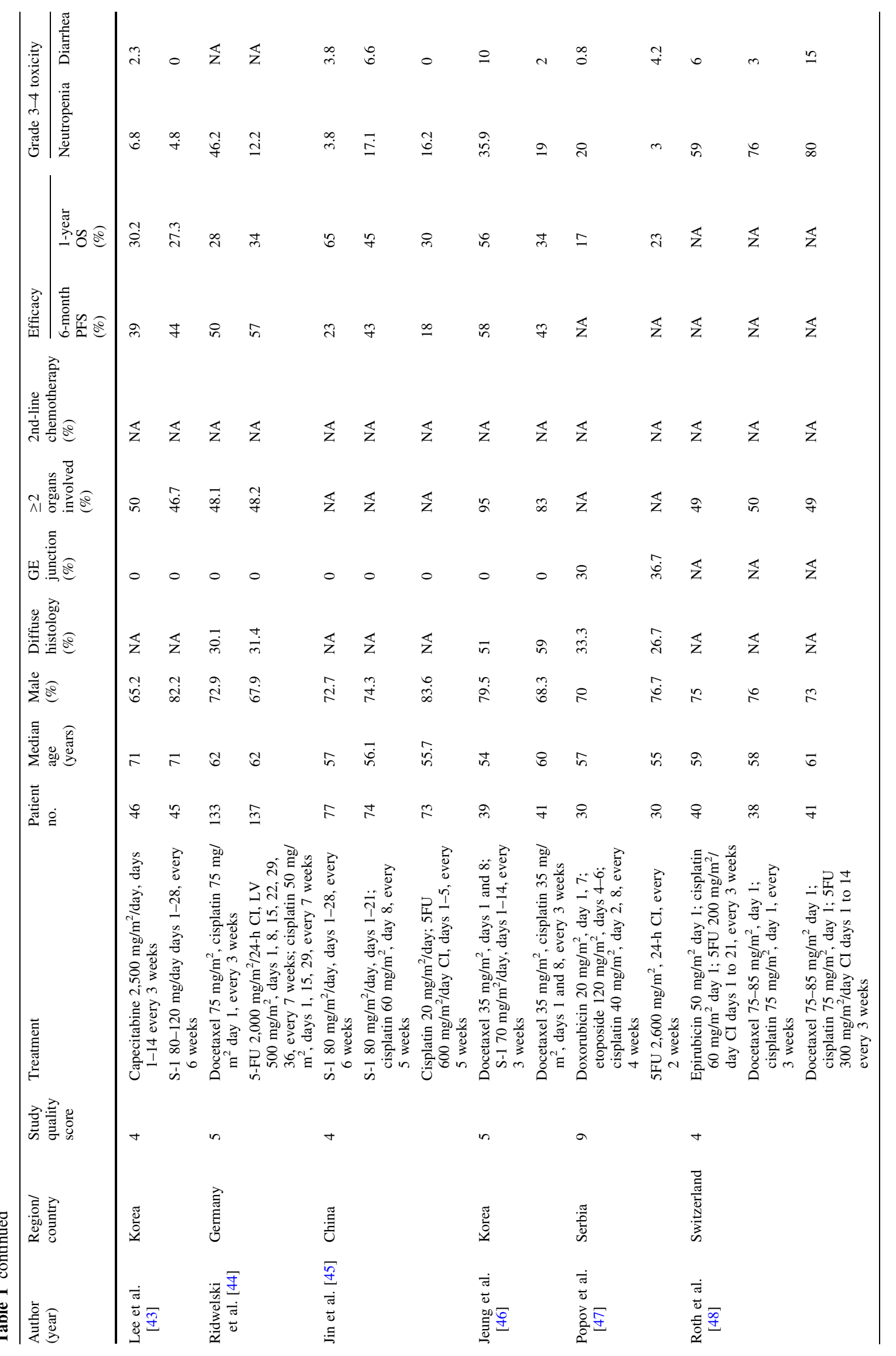




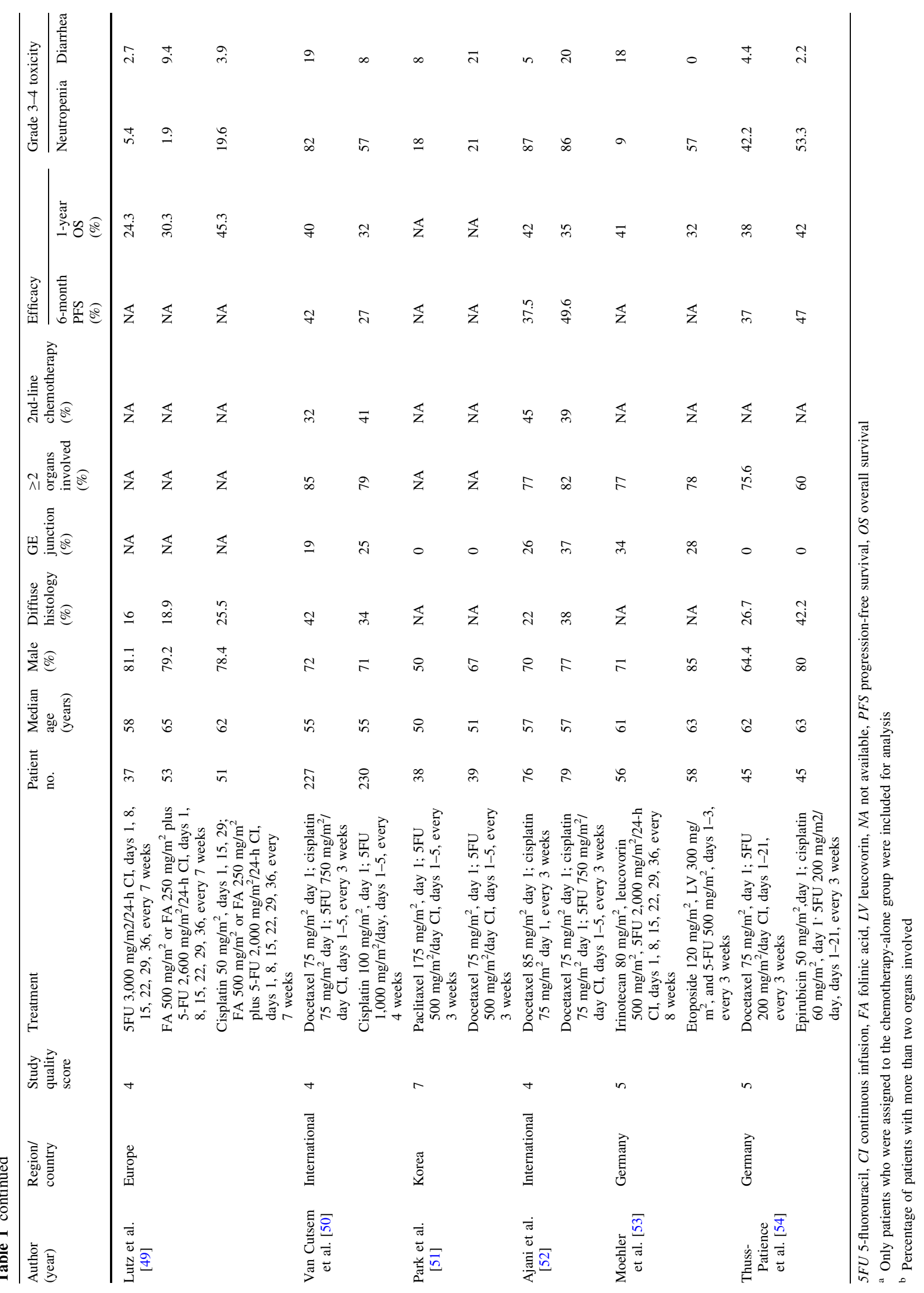



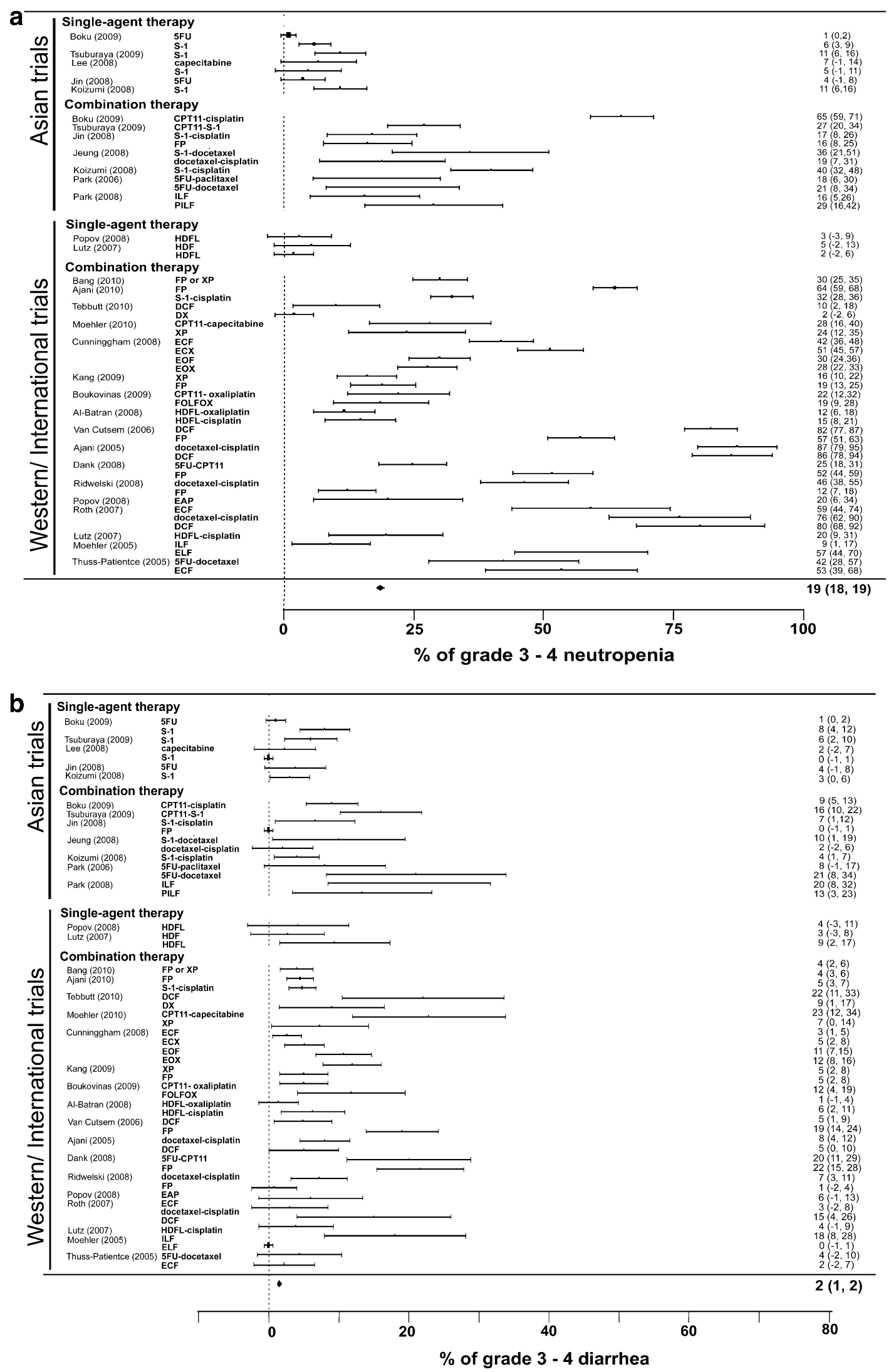

Fig. 2 Comparison of safety of systemic chemotherapy for advanced gastric cancer between the Asian and non-Asian trials 
Table 2 Predictors of safety of chemotherapy for patients with advanced gastric or gastroesophageal carcinoma

\begin{tabular}{|c|c|c|c|c|}
\hline Variable & Parameter estimate $^{\mathrm{a}}$ & SE & $t$ & $P$ value \\
\hline \multicolumn{5}{|c|}{ Incidence of grade 3-4 neutropenia $\left(R^{2} 0.704\right)$} \\
\hline Intercept & 0.114 & 0.011 & 9.975 & $<0.0001$ \\
\hline \multicolumn{5}{|l|}{ Patient/trial factor } \\
\hline Region (Asian vs. non-Asian trials) ${ }^{\mathrm{b}}$ & -0.082 & 0.012 & -6.866 & $<0.0001$ \\
\hline \multicolumn{5}{|l|}{ Treatment factor } \\
\hline 5FU (high-dose infusion) ${ }^{\mathrm{b}}$ & -0.123 & 0.014 & -8.879 & $<0.0001$ \\
\hline Cisplatin $^{\mathrm{b}}$ & 0.269 & 0.010 & 26.045 & $<0.0001$ \\
\hline Irinotecan $^{\mathrm{b}}$ & 0.217 & 0.016 & 13.806 & $<0.0001$ \\
\hline Taxanes $^{\mathrm{b}}$ & 0.100 & 0.013 & 7.626 & $<0.0001$ \\
\hline 3-drug combination ${ }^{\mathrm{b}}$ & 0.148 & 0.014 & 10.930 & $<0.0001$ \\
\hline \multicolumn{5}{|l|}{ Incidence of grade $3-4$ diarrhea $\left(R^{2} 0.708\right)$} \\
\hline Intercept & -0.065 & 0.012 & -5.359 & $<0.0001$ \\
\hline \multicolumn{5}{|l|}{ Patient/trial factor } \\
\hline Region (Asian vs. non-Asian trials) ${ }^{\mathrm{b}}$ & -0.021 & 0.004 & -5.793 & $<0.0001$ \\
\hline \multicolumn{5}{|l|}{ Treatment factor } \\
\hline 5FU (conventional infusion) $)^{\mathrm{b}}$ & 0.071 & 0.012 & 6.004 & $<0.0001$ \\
\hline 5FU (high-dose infusion) ${ }^{\mathrm{b}}$ & 0.079 & 0.015 & 5.353 & $<0.0001$ \\
\hline Oral fluoropyrimidines ${ }^{\mathrm{b}}$ & 0.093 & 0.012 & 7.659 & $<0.0001$ \\
\hline Cisplatin ${ }^{\mathrm{b}}$ & 0.021 & 0.004 & 5.854 & $<0.0001$ \\
\hline Oxaliplatin $^{\mathrm{b}}$ & 0.039 & 0.011 & 3.424 & 0.001 \\
\hline Irinotecan $^{\mathrm{b}}$ & 0.164 & 0.014 & 11.949 & $<0.0001$ \\
\hline Taxanes $^{\mathrm{b}}$ & 0.103 & 0.011 & 8.977 & $<0.0001$ \\
\hline Anthracycline ${ }^{\mathrm{b}}$ & 0.020 & 0.008 & 2.550 & 0.014 \\
\hline
\end{tabular}

a The parameter estimates indicate the effect size of each factor on the outcome. For categorical variables, the parameter estimates indicate the effect size with the presence of individual variables. For continuous variables, the parameter estimates indicate the effect size with each incremental unit of the particular variables

b Categorical variables

PFS are shown in Fig. 3. However, the meta-regression analysis does not identify geographic region as an independent predictor of either 1-year OS or 6-month PFS rates (Table 3).

Our meta-regression models indicate that two-drug and three-drug combination chemotherapy improves 6-month PFS rates, compared with a single-agent regimen, by 17.3 and $25.0 \%$, respectively. This finding may partly explain the better PFS rate reported by non-Asian trials, in which two-drug or three-drug combinations are more commonly used. As for individual chemotherapeutic agents, the use of high-dose infusional 5-FU, oral fluoropyrimidines, or taxanes is associated with independent improvement of PFS. A higher percentage of patients with gastroesophageal junctional carcinoma independently predicts a poor PFS rate. The meta-regression models indicate that the 6-month PFS will decrease by $4 \%$ for every $10 \%$ increase in patients with gastroesophageal junctional carcinoma.
The preliminary meta-regression analysis suggested that a higher percentage of patients with good performance status (ECOG score 0 or 1) was associated with poorer 1 -year OS, which is contradictory to previous reports [54]. Further meta-regression analysis by fitting a generalized additive model indicated that the data of ECOG performance status had a non-linear effect on the 1-year OS rate. A few trials having the highest percentage $(>95 \%)$ of patients with good performance status happened to report relatively poor 1-year OS (Online Resource Supplementary Figure). After adjusting for this non-linear relationship in our meta-regression analysis, the ECOG performance status loses its independent predictive value. The final metaregression model (Table 3) indicates that higher quality scores (indicating poor trial quality) and high median age are independent patient/trial factors that predict poor 1-year OS. While individual agents used in first-line chemotherapy may help predict OS, the meta-regression models 

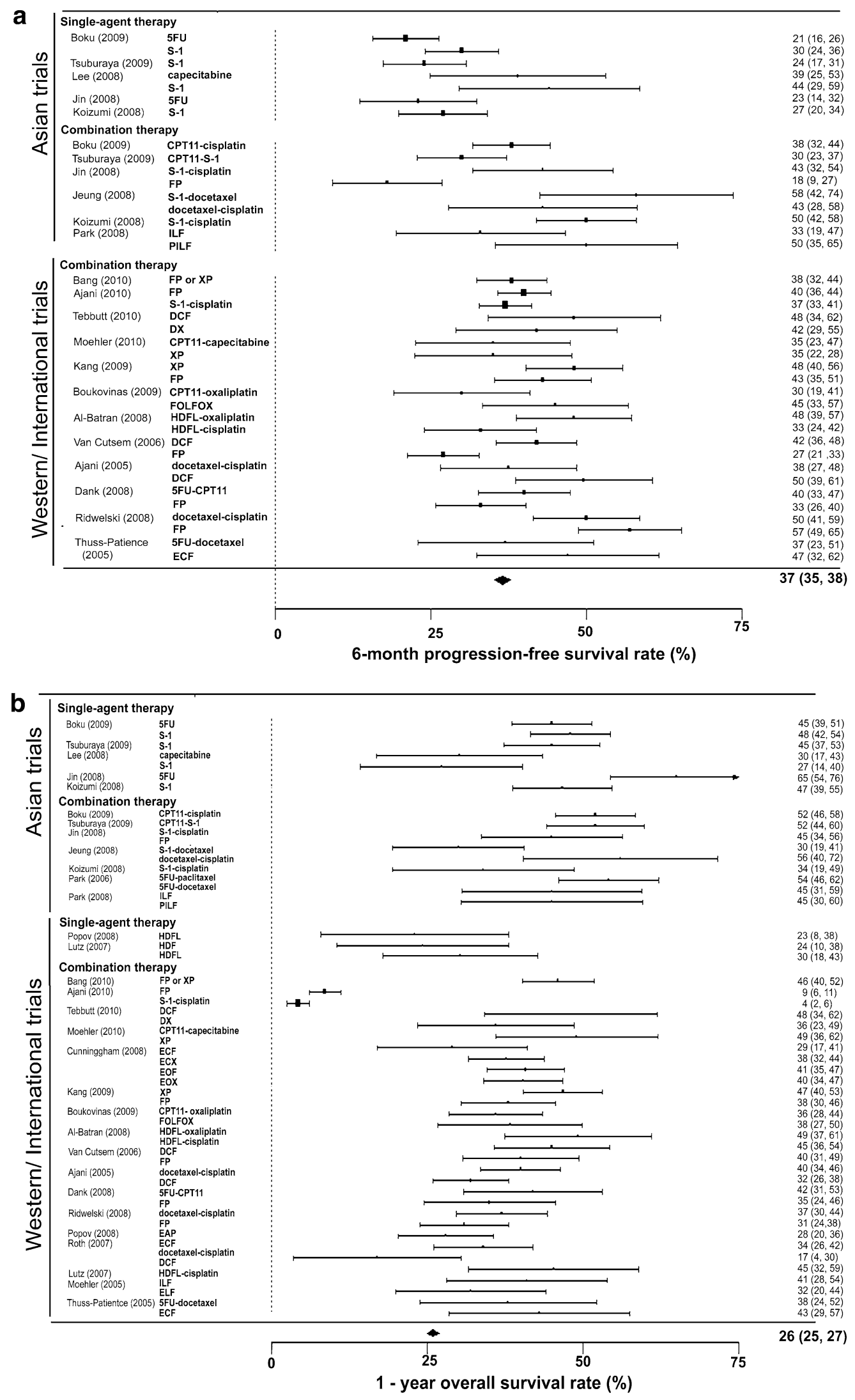

Fig. 3 Comparison of efficacy of systemic chemotherapy for advanced gastric cancer between the Asian and non-Asian trials 
Table 3 Predictors of treatment efficacy of chemotherapy for patients with advanced gastric or gastroesophageal carcinoma

\begin{tabular}{|c|c|c|c|c|}
\hline Variable & Parameter estimate & SE & $t$ & $P$ value \\
\hline \multicolumn{5}{|l|}{ 6-month progression-free survival rate $\left(R^{2} 0.737\right)$} \\
\hline Intercept & 0.319 & 0.046 & 6.999 & $<0.0001$ \\
\hline \multicolumn{5}{|l|}{ Patient/trial factor } \\
\hline Percentage of GE carcinoma ${ }^{a}$ & -0.004 & 0.001 & -4.563 & 0.0002 \\
\hline Percentage of patients with tumors involving 2 or more organs ${ }^{\mathrm{b}}$ & -0.001 & 0.001 & -1.954 & 0.063 \\
\hline \multicolumn{5}{|l|}{ Treatment factor } \\
\hline 5FU (high-dose infusion) ${ }^{\mathrm{a}}$ & 0.091 & 0.025 & 3.703 & 0.001 \\
\hline Oral fluoropyrimidines ${ }^{\mathrm{a}}$ & 0.056 & 0.017 & 3.422 & 0.002 \\
\hline Taxanes $^{\mathrm{a}}$ & 0.079 & 0.026 & 3.067 & 0.006 \\
\hline 2-drug combination & 0.173 & 0.022 & 7.870 & $<0.0001$ \\
\hline 3-drug combination & 0.250 & 0.043 & 5.843 & $<0.0001$ \\
\hline \multicolumn{5}{|l|}{ 1-year overall survival rate $\left(R^{2} 0.877\right)$} \\
\hline Intercept & 1.064 & 0.216 & 4.924 & 0.0001 \\
\hline \multicolumn{5}{|l|}{ Patient/trial factor } \\
\hline Trial quality score ${ }^{\mathrm{b}}$ & -0.052 & 0.020 & -2.584 & 0.019 \\
\hline Median age $\mathrm{e}^{\mathrm{b}}$ & -0.018 & 0.004 & -5.174 & $<0.0001$ \\
\hline \multicolumn{5}{|l|}{ Treatment factor } \\
\hline 5FU (high-dose infusion) ${ }^{\mathrm{a}}$ & 0.204 & 0.035 & 5.774 & $<0.0001$ \\
\hline Taxanes $^{\mathrm{a}}$ & 0.1954 & 0.029 & 6.732 & $<0.0001$ \\
\hline Anthracycline $^{\mathrm{a}}$ & 0.523 & 0.034 & 15.600 & $<0.0001$ \\
\hline Percentage of patients receiving second-line chemotherapy ${ }^{b}$ & 0.010 & 0.0004 & 23.881 & $<0.0001$ \\
\hline
\end{tabular}

a Categorical variables

${ }^{\mathrm{b}}$ Continuous variables

indicate that a higher percentage of patients who received second-line chemotherapy is an independent predictor for a better 1-year OS rate. The 1-year OS rate will increase by $10 \%$ for every $10 \%$ increase in patients who received second-line chemotherapy. A graphic representation of the effects of second-line chemotherapy on 1-year OS is shown in Fig. 4.

\section{Discussion}

Geographic region (Asian vs. non-Asian) has long been considered an important confounding factor for interpreting the results of clinical trials of systemic chemotherapy for advanced gastric cancer. The present study systematically explored the impact of different geographic regions, including the potential difference in patient characteristics and treatment patterns, on safety and efficacy reported by gastric cancer clinical trials. After controlling all the patient and treatment factors, geographic region remains an independent predictor of treatment safety in terms of chemotherapy-induced neutropenia and diarrhea. Future clinical trials of gastric cancer should consider the geographic region as a stratification factor to control potential bias.
The most recent example illustrating the confounding effects of geographic region on clinical trial results is the AVAGAST trial comparing the effects of chemotherapy with or without bevacizumab [55]. In that trial, Asian patients who received chemotherapy alone apparently had better overall survival (median 12.1 months) than the European (median 8.6 months) or the American counterparts (median 6.8 months). Two thirds of Asian patients received second-line treatment upon tumor progression, while only $31 \%$ of European patients and $21 \%$ of American patients did. While bevacizumab plus chemotherapy produced significantly better PFS and objective response rate, the benefit of bevacizumab on overall survival was only seen in American patients. These results support our findings that geographic regions and the associated confounders must be carefully evaluated in the design of clinical trials for gastric cancer.

One important issue in clinical trial design is the selection of the primary endpoint. Although overall survival is the gold standard, it is difficult for a new treatment to demonstrate overall survival advantage as first-line therapy when multiple options of second-line therapy are available. This issue is even more complicated in international clinical trials when the clinical practice of secondline therapy varies as widely as is seen in advanced gastric 
Fig. 4 Correlation between the use of second-line chemotherapy and 1-year overall survival rate. The size of individual circles represents the number of patients in each treatment group

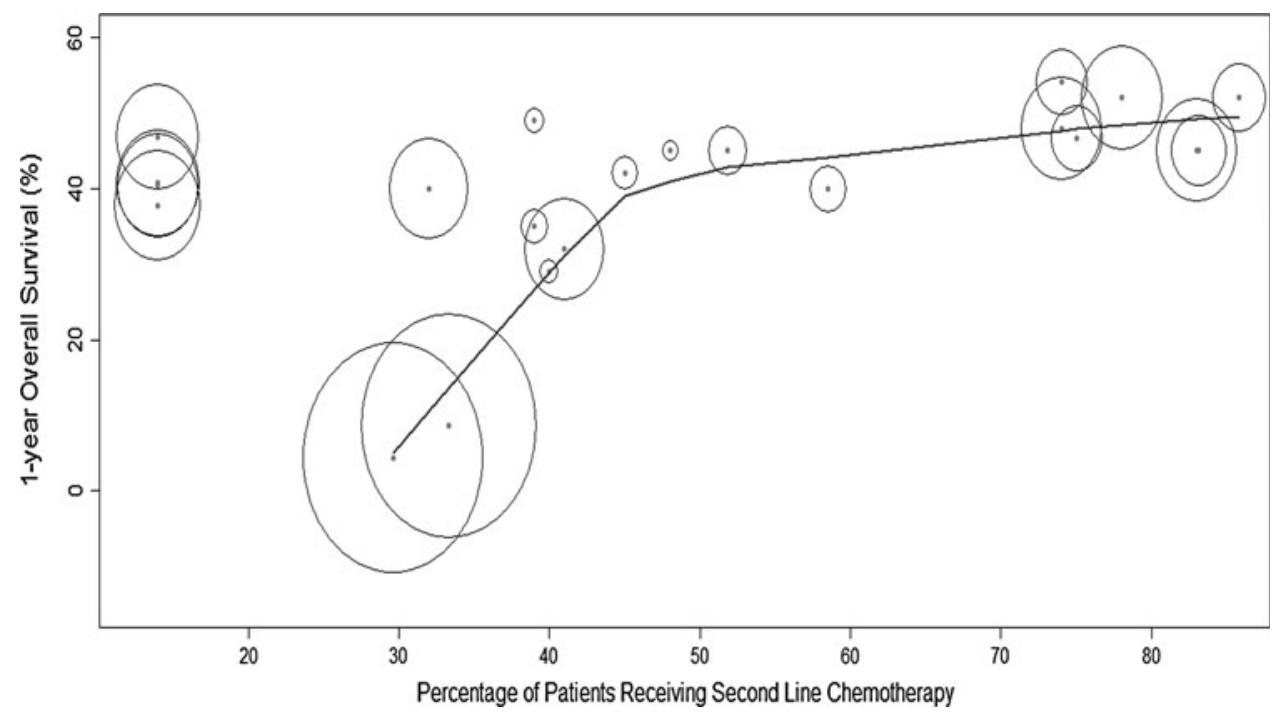

cancer. The use of surrogate endpoints, including PFS or time to tumor progression, to evaluate the efficacy of firstline treatment has been extensively studied in trials of colorectal and breast cancers, and data from many metaanalyses indicate that PFS is a good endpoint to evaluate the efficacy of first-line chemotherapy [56-58]. Standardization of evaluation of tumor progression is needed to validate the usefulness of these surrogate endpoints in trials of systemic therapy for gastric cancer [59].

Another important issue in clinical trial design is the selection of the optimal regimen as control. Our metaregression models indicate that no specific types of chemotherapeutic agents are clearly superior to others in terms of improvement in PFS, consistent with previous metaanalyses [1, 10, 60]. While multi-drug combinations produce higher PFS, the selection of chemotherapeutic regimens should also take into account treatment safety and impact on the patients' quality of life. The independent predictive value of geographic region on treatment safety strongly indicates an ethnic or genetic basis of the different safety profiles. Future international clinical trials should incorporate more detailed biomarker and pharmacogenetic studies to explore the optimal regimens for different ethnic groups.

Pharmacogenetic differences in drug targets and drugmetabolizing enzymes have been found to play important roles in both the efficacy and safety of fluororpyrimidines $[61,62]$. The potential impact of pharmacogenetic factors must be kept in mind when interpreting and extrapolating results comparing different fluoropyrimidine regimens. For example, capecitabine has shown overall survival benefit in randomized trials compared with conventional 5-FU infusion $\left(200 \mathrm{mg} / \mathrm{m}^{2} /\right.$ day by continuous infusion or $800 \mathrm{mg} /$ $\mathrm{m}^{2} /$ day for 5 days, every 3 weeks). S-1 has shown benefit in PFS and response rate compared with conventional 5-FU infusion $\left(800 \mathrm{mg} / \mathrm{m}^{2} /\right.$ day for 5 days every 4 weeks). Regarding the potential benefit of weekly or biweekly infusion of high-dose 5-FU and leucovorin, our previous studies suggested a pharmacodynamic basis for its higher response and lower toxicity compared with conventional bolus injection of 5-FU. The serum concentrations achieved by the high-dose infusional 5-FU schedule can suppress thymidylate synthase, the target enzyme of 5-FU, more sustainably, while the bone marrow concentrations achieved by this regimen did not produce significant toxicity to myeloid progenitor cells [63, 64]. The impact of pharmacogenetics on this regimen is not known. Comparative studies of genetic polymorphisms for drug targets and drug-metabolizing enzymes in Western and Asian patients should be incorporated into future clinical trials to better understand differences in toxicity and efficacy of fluoropyrimidines in Asian and non-Asian patients.

There are several important limitations of this study. First, because the control arm of the trials analyzed are very heterogeneous, it is difficult to compare the efficacy of different combination regimens by conventional metaanalysis. That is why we used the treatment arm-based approach. Second, many important factors, such as the histological subtypes, tumor extent at the start of chemotherapy, and content of second-line therapy, were not reported in many of the clinical trials analyzed. This significantly limits the numbers of factors that can be analyzed by meta-analysis and meta-regression. Third, meta-analysis based on aggregated patient data will suffer from the ecological bias. Future studies based on individual patient data are needed to verify the predictors identified in this study.

In conclusion, geographic region (Asian vs. non-Asian) plays an important role in the heterogeneity of clinical trials of gastric cancers and is an independent predictor of safety of systemic therapy for gastric cancer. 
Acknowledgments This study was supported by the grant NSC983112-B-002-007, NSC98-3112-B-002-037, from the National Science Council, Taiwan and DOH99-TD-C-111-001 from the Department of Health, Executive Yuan, Taiwan.

\section{References}

1. Wagner AD, Unverzagt S, Grothe W, Kleber G, Grothey A, Haerting J, et al. Chemotherapy for advanced gastric cancer. Cochrane Database Syst Rev. 2010;3:CD004064.

2. Ajani JA, Barthel JS, Bekaii-Saab T, Bentrem DJ, D'Amico TA, Das P, et al. Gastric cancer. J Natl Compr Cancer Netw. 2010;8(4):378-409.

3. Al-Batran SE, Ajani JA. Accomplishments in 2008 in the management of advanced gastroesophageal cancer. Gastrointest Cancer Res. 2009;3 5 Suppl 2:S58-61.

4. Shah MA, Ajani JA. Gastric cancer-an enigmatic and heterogeneous disease. JAMA. 2010;303(17):1753-4.

5. de Gramont A, Louvet C, André T, Tournigand C, Krulik M. A review of GERCOD trials of bimonthly leucovorin plus 5-fluorouracil 48-h continuous infusion in advanced colorectal cancer: evolution of a regimen. Eur J Cancer. 1998;34(5):619-26.

6. Milano G, Ferrero JM, François E. Comparative pharmacology of oral fluoropyrimidines: a focus on pharmacokinetics, pharmacodynamics and pharmacomodulation. Br J Cancer. 2004;91(4): 613-7.

7. Van Cutsem E, Hoff PM, Harper P, Bukowski RM, Cunningham $\mathrm{D}$, Dufour P, et al. Oral capecitabine vs intravenous 5-fluorouracil and leucovorin: integrated efficacy data and novel analyses from two large, randomised, phase III trials. Br J Cancer. 2004;90(6): 1190-7.

8. André T, Quinaux E, Louvet C, Colin P, Gamelin E, Bouche O, et al. Phase III study comparing a semimonthly with a monthly regimen of fluorouracil and leucovorin as adjuvant treatment for stage II and III colon cancer patients: final results of GERCOR C96.1. J Clin Oncol. 2007;25(24):3732-8.

9. Waters JS, Norman A, Cunningham D, Scarffe JH, Webb A, Harper $\mathrm{P}$, et al. Long-term survival after epirubicin, cisplatin and fluorouracil for gastric cancer: results of a randomized trial. $\mathrm{Br} \mathbf{J}$ Cancer. 1999;80(1-2):269-72.

10. Wagner AD, Grothe W, Behl S, Kleber G, Grothey A, Haerting J, et al. Chemotherapy for advanced gastric cancer. Cochrane Database Syst Rev. 2005;2:CD004064. doi:10.1002/14651858. CD004064.pub2.

11. Van Cutsem E, Moiseyenko VM, Tjulandin S, Majlis A, Constenla M, Boni C, et al. Phase III study of docetaxel and cisplatin plus fluorouracil compared with cisplatin and fluorouracil as firstline therapy for advanced gastric cancer: a report of the V325 study group. J Clin Oncol. 2006;24(31):4991-7.

12. Ohtsu A, Yoshida S, Saijo N. Disparities in gastric cancer chemotherapy between the East and West. J Clin Oncol. 2006; 24(14):2188-96.

13. Ma BB, Hui EP, Mok TS. Population-based differences in treatment outcome following anticancer drug therapies. Lancet Oncol. 2010;11(1):75-84.

14. Shah MA, Kelsen DP. Gastric cancer: a primer on the epidemiology and biology of the disease and an overview of the medical management of advanced disease. J Natl Compr Cancer Netw. 2010;8(4):437-47.

15. Gill S, Shah A, Le N, Cook EF, Yoshida EM. Asian ethnicityrelated differences in gastric cancer presentation and outcome among patients treated at a Canadian cancer center. J Clin Oncol. 2003;21(11):2070-6.
16. Al-Refaie WB, Tseng JF, Gay G, Patel-Parekh L, Mansfield PF, Pisters PW, et al. The impact of ethnicity on the presentation and prognosis of patients with gastric adenocarcinoma. Results from the National Cancer Data Base. Cancer. 2008;113(3):461-9.

17. Kim J, Sun CL, Mailey B, Prendergast C, Artinyan A, Bhatia S, et al. Race and ethnicity correlate with survival in patients with gastric adenocarcinoma. Ann Oncol. 2010;21(1):152-60.

18. Haller DG, Cassidy J, Clarke SJ, Cunningham D, Van Cutsem E, Hoff PM, et al. Potential regional differences for the tolerability profiles of fluoropyrimidines. J Clin Oncol. 2008;26(13): 2118-23.

19. Goh BC, Soo RA, Lim S, Zhang J, Furuie T, Urrea PD, et al. Inter-ethnic variability of $\mathrm{S}-1$ pharmacokinetics $(\mathrm{PK})$ and correlation with CYP2A6 phenotyping. J Clin Oncol. 2008;26 (May 20 suppl; abstract 2507).

20. Gandara DR, Kawaguchi T, Crowley J, Moon J, Furuse K, Kawahara M, et al. Japanese-US common-arm analysis of paclitaxel plus carboplatin in advanced non-small-cell lung cancer: a model for assessing population-related pharmacogenomics. J Clin Oncol. 2009;27(21):3540-6.

21. Schmid CH, Stark PC, Berlin JA, Landais P, Lau J. Metaregression detected associations between heterogenous treatment effects and study-level, but not patient-level, factors. J Clin Epidemiol. 2004;57(7):683-97.

22. Lambert PC, Sutton AJ, Abrams KR, Jones DR. A comparison of summary patient-level covariates in meta-regression with individual patient data meta-analysis. J Clin Epidemiol. 2002; 55(1):86-94.

23. Baker WL, White CM, Cappelleri JC, Kluger J, Coleman CI. Understanding heterogeneity in meta-analysis: the role of metaregression. Int J Clin Pract. 2009;63(10):1426-34.

24. Okines AF, Norman AR, McCloud P, Kang YK, Cunningham D. Meta-analysis of the REAL-2 and ML17032 trials: evaluating capecitabine-based combination chemotherapy and infused 5 -fluorouracil-based combination chemotherapy for the treatment of advanced oesophago-gastric cancer. Ann Oncol. 2009;20(9): 1529-34.

25. Higgins JPT, Green S, editors. Cochrane handbook for systematic reviews of interventions 4.2.6 (updated September 2006). In: The Cochrane library. Issue 4. Chichester: Wiley; 2006.

26. Whitehead A. Meta-analysis of controlled clinical trials. New York: Wiley; 2002.

27. Hastie T, Tibshirani R. Generalized additive models for medical research. Stat Methods Med Res. 1995;4:187-96.

28. Hsu C, Shen YC, Cheng CC, Hu FC, Cheng AL. Geographic difference in survival outcome for advanced hepatocellular carcinoma: implications on future clinical trial design. Contemp Clin Trials. 2010;31(1):55-61.

29. Shen YC, Hsu C, Chen LT, Cheng CC, Hu FC, Cheng AL. Adjuvant interferon therapy after curative therapy for hepatocellular carcinoma (HCC): a meta-regression approach. J Hepatol. 2010;52(6):889-94.

30. Bang YJ, Van Cutsem E, Feyereislova A, Chung HC, Shen L, Sawaki A, et al. Trastuzumab in combination with chemotherapy versus chemotherapy alone for treatment of HER2-positive advanced gastric or gastro-oesophageal junction cancer (ToGA): a phase 3, open-label, randomized controlled trial. Lancet. 2010;376:687-97.

31. Ajani JA, Rodriguez W, Bodoky G, Moiseyenko V, Lichinitser $\mathrm{M}$, Gorbunova V, et al. Multicenter phase III comparison of cisplatin/S-1 with cisplatin/infusional fluorouracil in advanced gastric or gastroesophageal adenocarcinoma study: the FLAGS trial. J Clin Oncol. 2010;28(9):1547-53.

32. Tebbutt NC, Cummins MM, Sourjina T, Strickland A, Van Hazel G, Ganju V, et al. Randomised, non-comparative phase II study of weekly docetaxel with cisplatin and 5-fluorouracil or with 
capecitabine in oesophagogastric cancer: the AGITG ATTAX trial. Br J Cancer. 2010;102(3):475-81.

33. Moehler M, Kanzler S, Geissler M, Raedle J, Ebert MP, Daum S, et al. A randomized multicenter phase II study comparing capecitabine with irinotecan or cisplatin in metastatic adenocarcinoma of the stomach or esophagogastric junction. Ann Oncol. 2010;21(1):71-7.

34. Boku N, Yamamoto S, Fukuda H, Shirao K, Doi T, Sawaki A, et al. Fluorouracil versus combination of irinotecan plus cisplatin versus S-1 in metastatic gastric cancer: a randomised phase 3 study. Lancet Oncol. 2009;10(11):1063-9.

35. Kang YK, Kang WK, Shin DB, Chen J, Xiong J, Wang J, et al. Capecitabine/cisplatin versus 5-fluorouracil/cisplatinas first-line therapy in patients with advanced gastric cancer: a randomised phase III noninferiority trial. Ann Oncol. 2009;20(4):666-73.

36. Boukovinas I, Androulakis N, Polyzos A, Vardakis N, Amarantidis $\mathrm{K}$, Bozionelou $\mathrm{V}$, et al. A randomized phase II trial of irinotecan plus oxaliplatin versus oxaliplatin, fluorouracil (5 FU), leukovorin (LV) as first-line treatment in advanced gastric cancer. J Clin Oncol. 2009;27:15s (suppl; abstract 4536).

37. Tsuburaya A, Narahara $H$, Imamura $H$, Hatake $K$, Imamoto $H$, Esaki $\mathrm{T}$, et al. Updated result on the 2.5-year follow-up of GC0301/TOP-002: randomized phase III study of irinotecan plus S-1 (IRI-S) versus S-1 alone as first-line treatment for advanced gastric cancer (AGC). J Clin Oncol. 2009;27:15s (suppl; abstract 4544).

38. Koizumi W, Narahara H, Hara T, Takagane A, Akiya T, Takagi $\mathrm{M}$, et al. S-1 plus cisplatin versus S-1 alone for first-line treatment of advanced gastric cancer (SPIRITS trial): a phase III trial. Lancet Oncol. 2008;9(3):215-21.

39. Cunningham D, Starling N, Rao S, Iveson T, Nicolson M, Coxon $\mathrm{F}$, et al. Capecitabine and oxaliplatin for advanced esophagogastric cancer. N Engl J Med. 2008;358(1):36-46.

40. Al-Batran SE, Hartmann JT, Probst S, Schmalenberg H, Hollerbach S, Hofheinz R, et al. Phase III trial in metastatic gastroesophageal adenocarcinoma with fluorouracil, leucovorin plus either oxaliplatin or cisplatin: a study of the Arbeitsgemeinschaft Internistische Onkologie. J Clin Oncol. 2008;26(9):1435-42.

41. Dank M, Zaluski J, Barone C, Valvere V, Yalcin S, Peschel C, et al. Randomized phase III study comparing irinotecan combined with 5-fluorouracil and folinic acid to cisplatin combined with 5-fluorouracil in chemotherapy naïve patients with advanced adenocarcinoma of the stomach or esophagogastric junction. Ann Oncol. 2008;19(8):1450-7.

42. Park SH, Nam E, Park J, Cho EK, Shin DB, Lee JH, et al. Randomized phase II study of irinotecan, leucovorin and 5-fluorouracil (ILF) versus cisplatin plus ILF (PILF) combination chemotherapy for advanced gastric cancer. Ann Oncol. 2008;19(4):729-33.

43. Lee JL, Kang YK, Kang HJ, Lee KH, Zang DY, Ryoo BY, et al. A randomised multicentre phase II trial of capecitabine vs. S-1 as first-line treatment in elderly patients with metastatic or recurrent unresectable gastric cancer. Br J Cancer. 2008;99(4):584-90.

44. Ridwelski K, Fahlke J, Kettner E, Schmidt C, Keilholz U, Quietzsch D, et al. Docetaxel-cisplatin (DC) versus 5-fluorouracilleucovorin-cisplatin (FLC) as first-line treatment for locally advanced or metastatic gastric cancer: preliminary results of a phase III study. J Clin Oncol. 2008;26 (May 20 suppl; abstract 4512).

45. Jin M, Lu H, Li J, Shen L, Chen Z, Shi Y, et al. Randomized 3-armed phase III study of S-1 monotherapy versus S-1/CDDP (SP) versus 5-FU/CDDP (FP) in patients (pts) with advanced gastric cancer (AGC): SC-101 study. J Clin Oncol. 2008;26 (May 20 suppl; abstract 4533).

46. Jeung H, Im C, Rha S, Ahn J, Shin S, Noh S, et al. A randomized phase II trial of docetaxel plus S-1 versus docetaxel plus cisplatin in advanced gastric cancer as a first-line treatment. J Clin Oncol. 2008;26 (May 20 suppl; abstract 4534).

47. Popov IP, Jelic SB, Krivokapic ZV, Jezdić SD, Pesko PM, Micev MT, et al. Bimonthly $24 \mathrm{~h}$ infusion of high-dose 5-fluorouracil vs EAP regimen in patients with advanced gastric cancer. A randomized phase II study. Med Oncol. 2008;25(1):73-80.

48. Roth AD, Fazio N, Stupp R, Falk S, Bernhard J, Saletti P, et al. Docetaxel, cisplatin, and fluorouracil; docetaxel and cisplatin; and epirubicin, cisplatin, and fluorouracil as systemic treatment for advanced gastric carcinoma: a randomized phase II trial of the Swiss Group for Clinical Cancer Research. J Clin Oncol. 2007;25(22):3217-23.

49. Lutz MP, Wilke H, Wagener DJ, Vanhoefer U, Jeziorski K, Hegewisch-Becker S, et al. Weekly infusional high-dose fluorouracil (HD-FU), HD-FU plus folinic acid (HD-FU/FA), or HDFU/FA plus biweekly cisplatin in advanced gastric cancer: randomized phase II trial 40953 of the European Organisation for Research and Treatment of Cancer Gastrointestinal Group and the Arbeitsgeme inschaft Internistische Onkologie. J Clin Oncol. 2007;25(18):2580-5.

50. Park SH, Lee WK, Chung M, Lee Y, Han SH, Bang SM, et al. Paclitaxel versus docetaxel for advanced gastric cancer: a randomized phase II trial in combination with infusional 5-fluorouracil. Anticancer Drugs. 2006;17(2):225-9.

51. Ajani JA, Fodor MB, Tjulandin SA, Moiseyenko VM, Chao Y, Cabral Filho S, et al. Phase II multi-institutional randomized trial of docetaxel plus cisplatin with or without fluorouracil in patients with untreated, advanced gastric, or gastroesophageal adenocarcinoma. J Clin Oncol. 2005;23(24):5660-7.

52. Moehler M, Eimermacher A, Siebler J, Höhler T, Wein A, Menges M, et al. Randomised phase II evaluation of irinotecan plus high-dose 5-fluorouracil and leucovorin (ILF) vs. 5-fluorouracil, leucovorin, and etoposide (ELF) in untreated metastatic gastric cancer. Br J Cancer. 2005;92(12):2122-8.

53. Thuss-Patience PC, Kretzschmar A, Repp M, Kingreen D, Hennesser D, Micheel S, et al. Docetaxel and continuous-infusion fluorouracil versus epirubicin, cisplatin, and fluorouracil for advanced gastric adenocarcinoma: a randomized phase II study. J Clin Oncol. 2005;23(3):494-501.

54. Chau I, Norman AR, Cunningham D, Waters JS, Oates J, Ross PJ. Multivariate prognostic factor analysis in locally advanced and metastatic esophago-gastric cancer- pooled analysis from three multicenter, randomized, controlled trials using individual patient data. J Clin Oncol. 2004;22:2395-403.

55. Kang Y, Ohtsu A, Van Cutsem E, Rha SY, Sawaki A, Park S, et al. AVAGAST: a randomized, double-blind, placebo-controlled, phase III study of first-line capecitabine and cisplatin plus bevacizumab or placebo in patients with advanced gastric cancer (AGC). J Clin Oncol. 2010;28:18s (suppl; abstract LBA4007).

56. Tang PA, Bentzen SM, Chen EX, Siu LL. Surrogate end points for median overall survival in metastatic colorectal cancer: literature-based analysis from 39 randomized controlled trials of first-line chemotherapy. J Clin Oncol. 2007;25(29):4562-8.

57. Buyse M, Burzykowski T, Carroll K, Michiels S, Sargent DJ, Miller LL, et al. Progression-free survival is a surrogate for survival in advanced colorectal cancer. J Clin Oncol. 2007;25(33):5218-24.

58. Sherrill B, Amonkar M, Wu Y, Hirst C, Stein S, Walker M, et al. Relationship between effects on time-to-disease progression and overall survival in studies of metastatic breast cancer. $\mathrm{Br} \mathrm{J}$ Cancer. 2008;99(10):1572-8.

59. Dancey JE, Dodd LE, Ford R, Kaplan R, Mooney M, Rubinstein $\mathrm{L}$, et al. Recommendations for the assessment of progression in randomised cancer treatment trials. Eur J Cancer. 2009;45(2):281-9. 
60. Pozzo C, Ohashi Y. Meta-analyses of randomized trials assessing the influence of chemotherapy and prognostic factor in advanced/ recurrent gastric cancer. J Clin Oncol. 2009;27:15s (suppl; abstract 4550).

61. Hoff PM, Saad ED, Ajani JA, Lassere Y, Wenske C, Medgyesy D. et al: Phase I study with pharmacokinetics of S-1 on an oral daily schedule for 28 days in patients with solid tumors. Clin Cancer Res. 2003;9:134-42.

62. Goekkurt E, Al-Batran S, Hartmann JT, Mogck U, Schuch G, Kramer M, et al. Pharmacogenetic analyses of a phase III trial in metastatic gastroesophageal adenocarcinoma with fluorouracil and leucovorin plus either oxaliplatin or cisplatin: a Study of the
Arbeitsgemeinschaft Internistische Onkologie. J Clin Oncol. 2009;27:2863-73.

63. Yeh KH, Yeh SH, Chang YS, Cheng AL. Minimal toxicity to myeloid progenitor cells of weekly 24-h infusion of high-dose 5-fluorouracil: direct evidence from colony forming unit-granulocyte and monocyte (CFU-GM) clonogenic assay. Pharmacol Toxicol. 2000;86(3):122-4.

64. Yeh KH, Yeh SH, Hsu CH, Wang TM, Ma IF, Cheng AL. Prolonged and enhanced suppression of thymidylate synthase by weekly 24-h infusion of high-dose 5-fluorouracil. Br J Cancer. 2000;83(11):1510-5. 